\author{
Cadernos de \\ ESTUDOS LINGǘlSTICOS - (54.2), Campinas, Jul./Dez. 2012
}

\title{
DISTRIBUTIVIDADE: O CASO DOS NUMERAIS REDUPLICADOS EM KARITIANA ${ }^{\text {*** }}$
}

\author{
ANA MÜLLER*
}

\begin{abstract}
RESUMO
Este artigo investiga interpretações distributivas de sentenças com e sem operadores distributivos abertos em karitiana frente a duas teorias semânticas: uma que propõe que a fonte da distributividade é a existência de um operador distributivo (cf. Link 1983, 1987 e Lasersohn 1995, 1998, entre outros) e outra que propõe duas fontes possíveis para a distributividade - plural lexical e pluralização do sintagma verbal (cf. Kratzer 2003, 2005). Em particular, o artigo investiga a semântica dos numerais distributivos em karitiana. $\mathrm{O}$ artigo conclui que interpretações distributivas são geradas de pelo menos duas maneiras nessa língua e possivelmente em todas as línguas humanas: cumulatividade (plural) lexical e pluralização do predicado. Em particular, para o karitiana, defendemos que os numerais distributivos pluralizam eventos e determinam a cardinalidade do argumento nominal interno do sintagma distribuído.
\end{abstract}

Palavras chave: distributividade; numerais distributivos; línguas indígenas.

\begin{abstract}
This paper investigates distributive interpretations of karitiana sentences with and without overt distributive operators, and confronts their behavior with two semantic theories: one which argues for the existence of a distributive operator as the only source of distributive readings (Link 1983, 1987 and Lasersohn 1995, 1998, among others), and another which claims that there are two possible sources of distributivity - lexical plural and pluralization of the verbal phrase (Kratzer 2003, 2005). More specifically, the paper investigates the semantics of distributive numerals in karitiana. We conclude that distributive interpretations are generated in at least two ways in this language and possibly in all human languages: lexical cumulativity (plurality) and predicate pluralization. Particularly, with reference to
\end{abstract}

${ }^{*}$ USP/CNPq, São Paulo, (SP), Brasil. anamuler@usp.br

**Agradeço aos participantes do Third International Conference on Bare Nouns (Rio de Janeiro 2011) e do Research Seminar on Nominal and Verbal Plurality (Paris 2009) por seus comentários quando da apresentação de diferentes versões deste trabalho. Agradeço também a um parecerista anônimo por suas sugestões e ao CNPq (303407/2009-3) pelo financiamento parcial desta pesquisa.

${ }^{1}$ A apresentação dos dados é feita da seguinte forma: $1^{\mathrm{a}}$ linha: transcrição ortográfica da sentença em Karitiana; $2^{\mathrm{a}}$ linha: segmentação morfológica; $3^{\mathrm{a}}$ linha: glosa morfema a morfema; $4^{\mathrm{a}}$ linha: tradução. Os morfemas foram abreviados da seguinte forma: NFT =não-futuro, $\mathrm{FT}=$ futuro; RDPL=reduplicação, DECL $=$ declarativo, $1 \mathrm{~s}=$ concordância de $1^{\mathrm{a}}$ pessoa do singular, $2 \mathrm{~s}=$ concordância de $2^{\mathrm{a}}$ pessoa do singular, $3=$ concordância de $3^{\mathrm{a}}$ pessoa, $\mathrm{OBL}=$ oblíquo, CAUS=causativo, $\mathrm{POS}=$ posposição, sUB=subordinador, $\mathrm{VT}$ = vogal temática. 
MÜLLER - Distributividade: o caso dos numerais reduplicados em Karitiana

Karitiana, it is claimed that distributive numerals like myhint myhint ('one one'), pluralize events and determine the cardinality of the internal argument of the distributed predicate.

Key-words: distributivity; distributive numerals; native American languages.

\section{INTRODUÇÃO}

Este artigo enfoca modos de expressão da distribuição nas línguas naturais e, em particular, na língua karitiana. Distributividade é uma operação que atribuí a cada parte de um distribuidor uma quantidade determinada do que é distribuído. Um exemplo de sentenças distributivas no português são sentenças como (1) e (2). A sentença (1) distribui uma entrega de dois trabalhos por aluno e a sentença (3) distribui entradas de três alunos por ocasião ('vez'). Nessas sentenças, temos operadores distributivos explícitos, como 'cada' na sentença (1), e 'de três em três' na sentença (2).

(1) Cada aluno entregou dois trabalhos.

(2) Os alunos entraram na sala de três em três.

Interpretações distributivas também podem ocorrer sem operadores explícitos como uma das leituras da sentença (3). Nessa interpretação, cada menina bebeu uma cerveja e cada menino bebeu quatro cervejas. Uma interpretação distributiva também é possível para uma sentença como (4), no sentido de que a sentença seria verdadeira, por exemplo, em uma situação (entre outras) em que cada menino bebeu duas cervejas e cada menina bebeu três coca-colas, ou seja, uma situação distributiva.

(3) $\mathrm{Na}$ festa, as meninas beberam uma cerveja e os meninos quatro.

(4) Na festa, menino bebeu cerveja e menina bebeu coca-cola.

Neste artigo vamos investigar as interpretações distributivas de sentenças como (5) e (6) da língua karitiana e vamos nos perguntar como são geradas as interpretações desses tipos de sentença. E, ao investigar essa questão, pretendemos enfrentar a questão teórica mais ampla de se a distributividade é uma mera consequência da interação entre os significados lexicais plurais de nomes e de verbos ou se ela é gerada por uma operação particular. E, se gerada por uma operação particular, qual seria essa operação.

$\begin{array}{cll}\text { (5) Õmbaky } & \text { naka'yt } & \text { pikom. }{ }^{2} \\ \text { ombaky } & \text { naka-'y-t } & \text { pikom } \\ \text { onça } & \text { 3p-DECL-comer-NFT } & \text { macaco }^{3}\end{array}$

${ }^{2} \mathrm{O}$ tempo não-futuro em karitiana será, na maioria das vezes, traduzido pelo passado neste trabalho, apesar de também significar presente.

${ }^{3}$ Ver Müller \& Sanchez-Mendes 2010 sobre a metodologia utilizada. 
'A/ Uma onça comeu o/um macaco'

'As/ Umas onças comeram os/uns macaco'

'A/ Uma onça comeu os/uns macacos'

'As/ Umas onças comeram o/um macaco'

Literalmente: 'Onça come/comeu macaco'

$\begin{array}{llll}\text { (6) Myhint.myhint } & \text { õmbaky } & \text { naka'yt } & \text { pikom. } \\ \text { Myhim-t.myhim-t } & \text { ómbaky } & \text { Ø-naka-'y-t } & \text { pikom } \\ \text { um-OBL.um-OBL } & \text { onça } & \text { 3-DECL-comer-NFT } & \text { macaco }\end{array}$

'Cada onça comeu um macaco'/‘Onças comeram um macaco de cada vez'

Mais especificamente, vamos examinar o comportamento desses dois tipos de sentenças distributivas em karitiana frente a duas teorias semânticas: uma que propõe a existência de um operador distributivo (cf. Link 1983, 1987 e Lasersohn 1995, 1998, entre outros) e outra que propõe duas fontes possíveis para a distributividade - plural lexical e operação sobre o sintagma verbal (SV) (cf. Kratzer 2003, 2005). Após esse percurso, concluiremos, concordando com Kratzer, que interpretações distributivas são geradas de pelo menos duas maneiras em karitiana e possivelmente em todas as línguas humanas: cumulatividade (plural) lexical e pluralização do predicado. Em particular, para o karitiana, vamos propor que numerais distributivos, como myhint myhint exemplificado em (6), pluralizam eventos e determinam a cardinalidade do argumento nominal do sintagma distribuído.

Os dados apresentados no trabalho foram coletados pela autora em trabalho de campo, a não ser se explicitamente mencionado em contrário. Os dados foram obtidos por meio de elicitação controlada e também por busca em textos orais já transcritos. Os dados assim obtidos foram checados com mais de um consultor. ${ }^{4}$

$\mathrm{O}$ texto está estruturado da seguinte forma. $\mathrm{Na}$ seção 2 apresentamos uma descrição mínima dos aspectos da língua karitiana necessários para a discussão dos fenômenos a serem investigados. Na seção 3 apresentamos as questões teóricas que formam o pano de fundo deste trabalho. A seção 4 analisa a semântica de sentenças do karitiana em que não há um operador distributivo explícito e para as quais uma interpretação distributiva é possível. Já na seção 5 , apresentamos a semântica dos numerais distributivos e a comparamos à semântica das interpretações distributivas em sentenças sem operadores aparentes. A seção 6 apresenta uma análise para sentenças com numerais distributivos. Argumentos sintáticos e semânticos que apoiam essa análise são apresentados na seção 7 . Finalmente, na seção 8, as conclusões são retomadas.

${ }^{4}$ Estamos usando o termo sintagma nominal (SN) de modo a incluir tanto SNs strictu sensu como sintagmas de determinante (SDs). Com isso, queremos deixar em aberto a questão de se o karitiana possui ou não SDs. 


\section{SOBRE A GRAMÁTICA DO KARITIANA}

Nesta seção, descrevemos alguns fatos relevantes da gramática do karitiana com a finalidade de fornecer ao leitor o contexto necessário para a compreensão dos exemplos e questões discutidas no artigo. Karitiana é uma língua nativa brasileira, a última sobrevivente da subfamília Arikém, da família Tupi. Os karitiana tem sua reserva em Rondônia, a aproximadamente 100 km de Porto Velho. Karitiana é atualmente falada por aproximadamente 400 pessoas como sua primeira língua (cf. Renato Karitiana c.p.). A maioria da população karitiana também fala o português com maior ou menor grau de fluência.

A língua karitiana é especialmente interessante para se realizar uma investigação sobre a distributividade. Em primeiro lugar, porque se trata de uma língua tipologicamente distante das línguas indo-européias em que se baseiam a maioria das teorias lingüísticas. Em segundo lugar, porque certas características dessa língua a tornam especialmente relevante para o estudo do plural e da distribuição, quais sejam:

(i) Ausência de marcação de número no sintagma nominal (SN). ${ }^{5}$ Como veremos na seção 3, nas línguas românicas e germânicas, o plural do SN é o que faz surgir a leitura plural/distributiva do predicado verbal. Que operador(es) seria(m) responsável(is) por gerar a leitura plural do predicado verbal em línguas como o karitiana nas quais o plural nominal inexiste?

(ii) Ausência de quantificação nominal. O estudo da distribuição está fortemente ancorado em quantificadores nominais do tipo 'cada' e 'todo'. De que modo línguas que não possuem quantificadores no sintagma nominal, como o karitiana, realizam operações de distribuição semelhantes às que fazem as línguas indo-européias com seus quantificadores nominais?

(iii) Numerais distributivos. Numerais distributivos realizam operações distributivas aparentemente semelhantes à realizada por quantificadores nominais como 'todo' e ‘cada'. Essa aparente semelhança é real ou trata-se de operações distintas que produzem coincidentemente um mesmo resultado?

Karitiana é uma língua cuja ordem básica é complemento-núcleo. Assim, o verbo ocupa a posição final em sentenças subordinadas (ver (7)). No entanto, em sentenças matrizes, no modo declarativo, o verbo ocupa canonicamente a segunda posição, como pode ser visto em (7) e nas sentenças (9), (10) e (11) mais abaixo.

$\begin{array}{cllll}\text { (7) }[\text { Ka'amat } & \text { Julenilza } & \text { manaty }] & \text { napating } & \text { João } \\ \text { Ka'amat } & \text { Julenilza } & \text { mana-ty } & \text { Ø-DECL-pating-Ø João } \\ \text { Logo } & \text { Julenilza } & \text { casar-OBL } & \text { 3-DECL-quer-NFT } & \text { João }\end{array}$

'João quer que Julenilza case logo'

${ }^{5}$ Ver Müller et al. 2006 para uma argumentação mais detalhada sobre a cumulatividade léxicas de substantivos e verbos em karitiana. 
Apesar de não marcar seus SNs para caso, karitiana segue um padrão de concordância chamado de ergativo-absolutivo: verbos intransitivos concordam com seus sujeitos e verbos transitivos concordam com seus objetos. Esse padrão está ilustrado pelo contraste entre a concordância em sentenças intransitivas como (8) e em sentenças transitivas como (9). Em (8) temos concordância de terceira pessoa com o sujeito (taso) e em (9) temos concordância de terceira pessoa com o objeto (pykom).

(8) Naahyt

Ø-na-ahy-t

3-DECL-beber-NFT

'O homem bebeu' taso

taso

homem

(9) $\mathrm{Yn}$

$$
\text { naka'yt }
$$

pikom.

yn

Ø-naka->y-t

pikom

$1 \mathrm{~s}$

3-DECL-comer-NFT

macaco

'Eu comi macaco'

Segundo Storto 2002, karitiana possui os seguintes modos: declarativo, assertivo, imperativo, citativo, deôntico e condicional. Ainda sabemos pouco sobre a semântica dos modos em karitiana. Neste artigo, discutiremos apenas a distributividade em sentenças matrizes no modo declarativo, que é marcado pelos morfemas na(ka)-, para a terceira pessoa, e ta(ka)-, para as outras pessoas, como exemplificado em (10) e (11).
(10) João
atakahit
presentety
João
a-taka-hit- $\varnothing$
presente-ty
João
2s-DECL-dar-NFT
'O João te deu um presente'
presente-OBL
(11) An
naka'yt
opokakosypi
an
$\varnothing$-naka-y-t
opok.ako.sypi
você
3-DECL-comer-NFT
ovo
'Você comeu ovo'

Karitiana possui dois marcadores morfológicos de tempo: o futuro e o não-futuro, como exemplificados em (7-11) e (12) abaixo. Neste trabalho, por simplicidade, restringiremos quase todos os nossos exemplos ao tempo não-futuro (NFT) que será sistematicamente traduzido como passado, apesar de também poder fazer referência ao tempo presente.
(12) An
ytaokyj.
Storto 2002
an
y-ta-oky-j
você
1s-DECL-matar-FT
'Você vai me matar' 
As denotações dos SNs em karitiana são sempre neutras para número (cumulativas), ou seja, incluem tanto entidades singulares como plurais, o que é ilustrado pelas interpretações possíveis de uma sentença como (5) acima que descreve situações que podem envolver tanto eventos e entidades singulares como situações que podem envolver eventos e entidades plurais ou qualquer outra combinação dessas duas possibilidades ${ }^{6}$.

Além disso, os SNs em karitiana são sempre nus. Nessa língua não ocorrem itens lexicais funcionais no sistema nominal, na sintaxe superficial. A língua não possui artigos, quantificadores nominais do tipo cada e todo, classificadores ou morfologia de gênero e número em seu SN. SNs nus como os da sentença (14) acima (ombaky e pykom) podem ser entendidos como definidos ou indefinidos, singulares ou plurais, como ilustrado pelas traduções possíveis. Neste artigo, as traduções apresentadas para as sentenças com nomes nus, não são sempre as únicas possíveis, mas sim aquelas que foram apresentadas ao consultor indígena para tradução, ou aquelas que foram as traduções apresentadas para os consultores indígenas para sentenças fornecidas pelas pesquisadoras.

Diferentemente do português, do inglês e de outras línguas indo-européias que expressam a quantificação universal através de quantificadores nominais como cada e todo, no português, e each, every e all, no inglês, a quantificação universal em karitiana é expressa através de uma oração relativa como ilustrado em (13). ${ }^{7}$ Note-se que esta sentença não é necessariamente distributiva, pois todos os homens podem ter matado juntos a mesma cobra. Assim quantificação universal e distributividade são fenômenos distintos, embora co-ocorram em muitas sentenças nas línguas naturais.

$\begin{array}{clll}\text { (13) Taso } & \text { akatyym } & \text { napopi } & \text { boroja } \\ \text { Taso } & \text { aka-tyym } & \text { Ø-na-popi- } \varnothing & \text { boroja } \\ \text { Homem } & \text { ser-suB } & \text { 3-DECL-matar-NFT } & \text { cobra }\end{array}$

'Todos os homens mataram cobra'

Finalmente, resta mencionar que karitiana possui numerais distributivos que são expressões como a ilustrada em (6). Discutiremos essas expressões em mais detalhe na seção 4.

Uma vez apresentadas as características da gramática do Karitiana que são relevantes para este trabalho, passaremos, na próxima seção, à apresentação e discussão das teorias sobre a distributividade em semântica formal.

\section{CUMULATIVIDADE E DISTRIBUTIVIDADE}

Esta seção objetiva situar o problema teórico a ser enfrentado pelo artigo. Em particular, apresentamos as principais teorias sobre a distributividade e sobre

\footnotetext{
${ }^{6}$ Ver Coutinho-Silva 2005 e Müller et al 2006 sobre a análise da quantificação universal como oração relativa. Mais recentemente, Storto 2011 defende que as orações que expressão a quantificação universal em karitiana são orações adverbiais.
} 
o plural verbal. Um de nossos objetivos específicos é o de introduzir as noções de cumulatividade, de distributividade, de plural de eventos e de sua individuação como tratadas pela semântica formal, que são utilizadas no trabalho. Nesta seção, discutiremos apenas a semântica de sentenças do karitiana que, da mesma forma que a sentença (14) do português, não possuem operadores distributivos explícitos.

(14) Os meninos carregaram o piano.

A sentença (14) possui uma leitura coletiva na qual os meninos carregaram o piano juntos enquanto um grupo (ou uma pluralidade). Essa sentença possui também uma leitura distributiva na qual cada menino individualmente carregou o piano. Existem sentenças que possuem apenas leituras coletivas como, por exemplo, a sentença (15) abaixo. Uma leitura distributiva em que cada aluno se reuniu é impossível para essa sentença uma vez que é impossível reunir-se individualmente. A sentença (16), por outro lado, possui apenas uma leitura distributiva, pois não há como dormir se não individualmente.

(15) Os alunos se reuniram na sala 202.

(16) Os alunos dormiram na aula.

As leituras distributivas de uma sentença sem nenhum operador distributivo aparente, como a sentença (14), desde os trabalhos de Link 1983, 1987 e Roberts 1987, têm sido tratadas como resultado da aplicação de um operador distributivo abstrato $\left({ }^{D}\right)$, que pode ser opcionalmente adjungido a predicados. Conceitualmete, um predicado é distributivo se, quando ele se aplica a um grupo ou a uma pluralidade, ele necessariamente se aplica a cada um dos membros desse grupo ou pluralidade (p.ex., 'dormir'). Para essa teoria, uma sentença como (17a), tem sua leitura distributiva expressa pela forma lógica em (17b), cuja interpretação encontra-se em (17c) e pode ser parafraseada como Cada menino carregou o piano.

(17) a. Os meninos carregaram o piano.

b. ${ }^{\mathrm{D}}$ carregar.o.piano (os.meninos)

c. $\forall x[x \leq \text { os.meninos } \rightarrow \text { carregar.o.piano }(x)]^{7}$

Lasersohn 1995 e Schein 1993 adaptam o operador ${ }^{\mathrm{D}}$ de Link e Roberts para uma semântica de eventos. A idéia fundamental de uma semântica que incorpora eventos em sua ontologia é que predicados verbais contêm um argumento evento (ver Davidson 1967, Bach 1981 e Parsons 1990, entre outros). Esse tipo de semântica nos permite analisar a operação de distribuição nas línguas humanas como uma distribuição entre indivíduos e eventos e não apenas entre indivíduos, como em (25c), em que temos a distribuição como uma relação entre entidades que são meninos e entidades que carregaram o piano.

${ }^{7} \mathrm{X}$ : variável sobre entidades atômicas; Y: variável sobre entidades singulares (atômicas) e plurais; $\mathrm{xx}$ é igual a ou parte de $\mathrm{Y}$. 
MÜLLER - Distributividade: o caso dos numerais reduplicados em Karitiana

Ao incorporarmos eventos a nossa ontologia, podemos apresentar a distributividade também como uma relação entre entidades e eventos. Assim, a leitura distributiva da sentença (18a), quando traduzida para uma semântica que inclui distribuição de eventos, possui a forma lógica (18b) e é interpretada como (18c), ou seja, como uma relação entre as entidades que são meninos e os subeventos na denotação de carregar.o.piano. A interpretação em (18c) é também equivalente à da sentença Cada menino carregou o piano.

(18) a. Os meninos carregaram o piano.

b. ${ }^{\mathrm{D}}$ carregar.o.piano (os.meninos)(E)

c. $\exists E \forall \mathrm{x}\left[\mathrm{x} \leq \text { os.meninos } \rightarrow \exists e^{\prime}\left[e^{\prime} \leq E \text { \& carregar.o.piano }(\mathrm{x})\left(\mathrm{e}^{\prime}\right)\right]\right]^{8}$

Esse tratamento tradicional da distributividade possui duas características básicas. A primeira é a assunção de que se distribuem eventos atômicos por entidades atômicas. E a segunda é a assunção de que a distribuição implica em uma quantificação universal sobre o argumento distribuidor (em (18), os.meninos). Note-se que, para que a distribuição seja possível, é sempre necessário que tanto o argumento distribuidor como o argumento distribuído tenham denotações plurais.

Um outro tratamento para a distributividade foi proposto mais recentemente por Kratzer 2003, 2005. A autora mostra que a distributividade pode ser analisada como um efeito da cumulatividade de predicados lexicais e frasais. Para Kratzer, interpretações plurais e distributivas podem ser geradas de pelo menos duas maneiras distintas. Uma delas é a interação entre a cumulatividade inerente a todos os predicados básicos das línguas naturais. A outra fonte de significados plurais é a pluralização do sintagma verbal (SV).

Dizer que um predicado é cumulativo é dizer que sempre que podemos aplicálo a dois argumentos, podemos aplicá-lo também à soma desses dois argumentos. $\mathrm{O}$ predicado sanduíche (ou qualquer outro substantivo) em português brasileiro, por exemplo, é cumulativo e pode ser referir tanto a sanduíches atômicos (singulares) como a sanduíches plurais. Ilustramos a propriedade da cumulatividade usando sanduíche na sentença (19). Em uma situação em que Maria comeu três sanduíches ontem, a sentença (19) seria adequada. A sentença (19) também seria adequada para descrever uma situação em que Maria comeu apenas um sanduíche. Assim, vemos que o substantivo sanduíche pode fazer referência tanto a sanduíches singulares como a sanduíches plurais, sendo, portanto, um predicado cumulativo.

(19) Maria comeu sanduíche.

Para Kratzer, os predicados (nominais e verbais) já 'nascem' cumulativos, ou seja, contendo tanto átomos como pluralidades em sua denotação. Nesse sentido, no léxico, esses predicados são semanticamente plurais (apesar de não possuírem necessariamente morfologia de plural) (ver também Krifka 1992, Landmann 1996). De acordo com essa teoria, todas as interpretações de uma sentença como

\footnotetext{
${ }^{8}$ E: variável sobre eventos singulares e plurais, e': variável sobre eventos atômicos.
} 
(19), por exemplo, decorreriam apenas da interação entre a cumulatividade da denotação do verbo e a cumulatividade da denotação do substantivo. Uma sentença como (19) descreve tanto eventos singulares como eventos plurais e é verdadeira de situações singulares em que, p.ex., Maria comeu um sanduíche apenas uma vez; ou de situações plurais como, p.ex., situações em que Maria comeu mais de um sanduíche uma ou mais vezes. Assim, para esse tipo de sentença, não há necessidade de se postular um operador distributivo. Como o verbo comer e o substantivo sanduíche possuem denotações cumulativas, a interação entre ambas as denotações faz com que a sentença seja completamente indeterminada quanto ao número de eventos de comer e ao número de sanduíches comidos.

Para o inglês, e possivelmente para outras línguas, Kratzer 2003, 2005 defende que, além da cumulatividade lexical, existe pelo menos uma outra fonte de interpretações plurais e distributivas - a pluralização do sintagma verbal. A diferença entre esses dois tipos de plurais pode ser percebida pelo contraste entre as interpretações possíveis para as sentenças (20) e (21). As sentenças (20a) e (21a) são indeterminadas quanto ao número de menores cuidados. A sentença (20b), por outro lado, possui apenas uma interpretação coletiva, na qual um único menor é cuidado pelo time todo. Já (21b) é ambígua entre uma leitura singular (coletiva), em que existe apenas um menor que é cuidado por todos os jogadores, e uma leitura plural (distributiva) na qual cada jogador cuida de um menor diferente. O que seria responsável por desencadear a leitura distributiva do predicado em (21b), uma vez que ela não está presente em (20b) da qual (21b) difere minimamente?

(20) a. O time cuida de menor abandonado.

b. Para fazer caridade, o time cuida de um menor abandonado.

(21) a. Os jogadores cuidam de menor abandonado.

b. Para fazer caridade, os jogadores cuidam de um menor abandonado.

Vamos assumir com Kratzer 2003 que os eventos na denotação de um predicado são mínimos, ou seja, eles contem apenas os elementos que tornam a sentença verdadeira e nada mais. Assim, um evento de cuidar de um menor abandonado contém um único menor abandonado em sua denotação. Outros menores abandonados ou outras entidades de outros tipos não fazem parte desse evento mínimo. Por essa razão, um evento de cuidar de um menor abandonado nunca poderá conter mais de um menor, mesmo que esse evento seja um evento plural. Se houvesse mais de um menor abandonado nesse evento, teríamos um evento de 'cuidar de menores abandonados' e não um evento de 'cuidar de um menor abandonado'. Explica-se assim por que (20b) fala sempre do mesmo menor, independentemente de quantas vezes o evento for repetido.

A existência de um único evento na sentença (20b) mostra que a cumulatividade lexical é insuficiente para explicar como identificamos mais de um menor abandonado na leitura distributiva de (21b), pois (20b) descreve um evento singular. Kratzer conclui dessa argumentação que o sintagma verbal da sentença 
(21b) deve ter sido, então, pluralizado. Como a única diferença entre (20b) e (21b) é a pluralização do SN sujeito, Kratzer conclui também que a pluralização do SV foi introduzida pelo morfema plural [-s] do sujeito.

Outra teoria relevante para o estudo da distributividade e, mais especificamente, da pluralidade verbal é a de Lasersohn 1995 sobre o fenômeno da pluracionalidade. Pluracionalidade é um termo que descreve uma marcação morfológica no verbo indicando plural de eventos. Esse fenômeno está relacionado à distributividade porque (i) para haver distribuição é necessário haver plural; (ii) eventos plurais pressupõem um critério de individuação de eventos que, de certa forma, funciona como um distribuidor.

Segundo Lasersohn, um morfema pluracional, quando adicionado a um verbo, expressa que esse verbo denota um evento plural, cujos eventos atômicos podem ser individuados segundo o tempo ('vezes'), o espaço ou os participantes do evento. A forma lógica em (22) resume a proposta do autor. Ela expressa que todos os eventos denotados pelo verbo pluracionalizado devem ser do mesmo tipo dos eventos denotados pelo verbo singular e que o número desses eventos é maior que um padrão estabelecido contextualmente. Ilustramos o fenômeno com a sentença (23) do karitiana. Nela o morfema pluracional é uma duplicação da raiz verbal e o número de eventos deve ser maior que dois.

$\mathrm{V}-\mathrm{PA}(\mathrm{E}) \leftrightarrow \forall \mathrm{e} \in \mathrm{E}[\mathrm{V}(\mathrm{e}) \&|\mathrm{E}| \geq \mathrm{n}]^{9}$

(23) Pik

$\begin{array}{llll}\text { Pikom } & \text { kyynt } & \text { naponpon } & \text { owã. } \\ \text { pikom } & \text { kyynt } & \varnothing \text {-na-pon-pon- } & \text { ôwã } \\ \text { macaco } & \text { em } & \text { 3-DECL-atirar-DUPL-NFut } & \text { menino } \\ \text { 'Menino atirou em macaco mais de uma vez' } & \end{array}$

Resumindo, podemos dizer que existem atualmente duas teorias importantes sobre semântica da distributividade nas línguas naturais: (i) distributividade como quantificação universal sobre átomos (ver Link 1983, 1987, Lasersohn 1995, entre outros); e (ii) distributividade como conseqüência de cumulatividade lexical e da pluralização do sintagma verbal (ver Kratzer 2003, 2005). Em ambas as teorias, os predicados a serem distribuídos devem ser plurais (ou cumulativos). No primeiro caso, nomes e verbos são lexicalmente singulares (denotam apenas átomos) e são distribuídos na sintaxe. No segundo caso, nomes e verbos já nascem cumulativos e uma interpretação distributiva pode ser resultado seja de denotações cumulativas, seja de pluralização do sintagma verbal. Distributividade, por sua vez, exige plural de eventos. Vimos que esse plural pode ser morfologicamente marcado no verbo em algumas línguas, fenômeno esse chamado de pluracionalidade.

${ }^{9} \mathrm{~V}$ : verbo; PA: marcador pluracional; E: variável sobre eventos singulares e plurais; e: variável sobre eventos atômicos; n: variável sobre os números naturais; $|\mathrm{E}|$ : o número de elementos atômicos em E. 
Na próxima seção, vamos nos debruçar sobre casos de sentenças do karitiana para as quais as interpretações distributivas são uma mera conseqüência da cumulatividade lexical de suas palavras.

\section{DISTRIBUTIVIDADE GERADA POR CUMULATIVIDADE LEXICAL}

Esta seção discute as interpretações coletivas, cumulativas e distributivas de sentenças como (5), na língua karitiana. Seu objetivo é mostrar que todas essas interpretações são geradas pela combinação das denotações lexicais de verbos e nomes e que, portanto, para este caso, nenhum operador distributivo precisa ser postulado.

Como visto na seção 2, a cumulatividade é uma propriedade tanto de nomes quanto de verbos em karitiana. Assim, nomes e verbos são cumulativos em karitiana quando entram na estrutura sintática de uma sentença. Podemos então prever que as sentenças dessa língua que não forem submetidas a operações de número (através da presença de numerais ou de operadores distributivos, por exemplo) possuirão várias interpretações quanto ao número de indivíduos e de eventos envolvidos. Essa gama de interpretações está ilustrada acima nas traduções possíveis para a sentença (5). Como a sentença (5) é neutra quanto ao número de eventos e de indivíduos envolvidos na situação que ela descreve, ela será verdadeira para qualquer número de eventos em que um número qualquer de onças come um número qualquer de macacos. Essa interpretação está formalmente representada em $(22) \cdot{ }^{10}$

\section{(22) $\exists \mathrm{E} \exists \mathrm{X} \exists \mathrm{Y}[\operatorname{comer}(\mathrm{Y})(\mathrm{E}) \&$ agente $(\mathrm{X})(\mathrm{E})$ \& onça $(\mathrm{X})$ \& macaco(Y)]}

Em palavras: 'Existe um evento $\mathrm{E}$ e existe uma entidade $\mathrm{X}$ e existe uma entidade $\mathrm{Y}$, tal que E é um evento de comer $\mathrm{Y}$ e o agente desse evento é X e $\mathrm{X}$ é onça e Y é macaco.'

A representação lógica em (22) é verdadeira para situações que podem ser descritas como: (i) cumulativas - onças comeram macacos em várias combinações possíveis; (ii) coletiva - um grupo de onças comeu um grupo de macacos juntas; e (iii) distributivas: cada onça comeu um macaco, ou cada onça comeu dois macacos, etc.. Assumindo-se que os predicados onça, macaco, comer e agente são cumulativos, que onça e macaco, são predicados de um lugar e que comer e agente são predicados de dois lugares (chamados de relações), a representação

${ }^{10} \mathrm{E}$ : variável sobre eventos singulares e plurais; $\mathrm{X}$ e Y: variáveis sobre entidades singulares e plurais. A representação lógica em (33) deixa de lado as interpretações dos morfemas funcionais de tempo (NFT) e de modo (DECL), uma vez que elas não são relevantes para o trabalho desenvolvido neste artigo. Estamos adotando aqui o formalismo de Kratzer 2003, no qual ela postula que o argumento interno é um argumento do predicado verbal, ao passo que o argumento externo não é um argumento desse predicado. 
MÜLLER - Distributividade: o caso dos numerais reduplicados em Karitiana

lógica em (22) dá conta do fato de que a sentença (5) é verdadeira de uma série de situações, tais como as situações descritas neste parágrafo. ${ }^{11}$

Imaginemos um contexto em que tenhamos três onças (A, B e C) e três macacos (D, E e F). Em uma situação coletiva, as três onças comem os três macacos juntas. Em uma situação distributiva, as três onças comem cada uma um dos macacos. E, finalmente, existe a possibilidade de, por exemplo, uma onça comer dois macacos sozinha e as duas outras comerem juntas um outro macaco - uma situação cumulativa. Vamos considerar como um evento singular $\left(\mathrm{e}_{\mathrm{n}}\right)$ cada vez que um macaco é comido. Teremos então três eventos atômicos que compõem cada uma das situações exemplificadas. Note-se que qualquer uma dessas situações pode ser descrita como uma situação em que $\mathrm{A}+\mathrm{B}+\mathrm{C}$ comem $\mathrm{D}+\mathrm{E}+\mathrm{F}$ em $\mathrm{e}_{1}+\mathrm{e}_{2}+\mathrm{e}_{3}$ Os eventos singulares que compõem essas situações plurais são diferentes em cada caso, mas o resultado final é o mesmo tipo de evento plural - três onças comem três macacos - que pode ser descrito pela fórmula em (22).

Desse modo, vemos que a sentença Õmbaky naka'yt pikom possui tanto interpretações distributivas como coletivas e cumulativas e que essas interpretações são todas geradas pela cumulatividade lexical dos itens que a compõem. Vimos que a sentença (5) é verdadeira para qualquer número de eventos de comer macaco, e para qualquer número de onças e de macacos.

Por outro lado, na próxima seção, veremos que numerais distributivos geram apenas leituras distributivas. A questão que surge, então, é se as leituras distributivas geradas pela cumulatividade e as leituras distributivas geradas pelos numerais distributivos possuem a mesma semântica. Essa questão será tratada nas duas próximas seções.

\section{DISTRIBUTIVIDADE GERADA POR NUMERAIS REDUPLICADOS}

Nesta seção, vamos mostrar que as interpretações distributivas geradas pela cumulatividade lexical são diferentes daquelas geradas pelos numerais distributivos. No primeiro caso, vimos, na seção 4, que elas fazem parte do conjunto da gama de possíveis interpretações geradas pela cumulatividade do verbo e de seus argumentos. Já no caso dos numerais distributivos, ou reduplicados, veremos que a interpretação distributiva é gerada pela multiplicação dos eventos que são parte da denotação do predicado como um todo.

Numerais distributivos em karitiana são expressões distributivas formadas pelo uso de reduplicação de numerais, como as expressões myhint myhint e sypomp sypomp do karitiana na sentença (6), e na sentença (23) abaixo. Muitas línguas no mundo, pertencentes a famílias bastante distintas entre si, possuem numerais distributivos. Citamos como exemplos: gã, da família níger-congo e falada em Gana; burushaski, língua isolada, falada na Índia e no Paquistão; georgiano, da

${ }^{11}$ Para uma demonstração cuidadosa de que a fórmula em (33) é verdadeira nos três tipos de situações discutidas acima, ver Müller \& Negrão no prelo. 
família sul-caucasiana e falada na Geórgia; e comanche, da família uto-asteca e falada nos Estados Unidos (ver Gil 1982, 2011).

$\begin{array}{llll}\text { Õwã } & \text { nakakot } & \text { sypomp.sypomp } & \text { opokakosypi } \\ \text { õwã } & \varnothing \text {-naka-kot- } & \text { sypom-t.sypom-t } & \text { opok.ako.sypi } \\ \text { menino } & \text { 3-DECL-quebrar-NFT } & \text { dois-OBL.dois-OBL } & \text { ovo } \\ \text { 'Cada menino quebrou dois ovos'/ } & & \\ \text { 'Os meninos quebraram dois ovos de cada vez.' } & \end{array}$

Numerais distributivos lembram expressões adverbiais como 'de um em um' e 'de dois em dois' do português, como na sentença (24). No entanto, sua gama de interpretações é distinta. Como ilustração, vamos comparar as interpretações da sentença (23) do karitiana às interpretações da sentença (24) do português para que as questões em jogo fiquem mais claras. Para isso, acompanhamos as sentenças do português de uma paráfrase mais próxima de sua tradução para uma linguagem lógica.

(24) Meninos quebraram ovos de dois em dois.

a. 'Em cada ocasião, dois meninos quebraram ovos.'

b. 'Em cada ocasião, meninos quebraram dois ovos.'

A sentença (24) possui duas interpretações: uma na qual dois meninos de cada vez quebraram ovos (24a) e outra na qual dois ovos foram quebrados de cada vez por meninos (24b). Em termos mais técnicos, dizemos que, em (24a), o distribuidor são ocasiões ('vezes') e o distribuído são eventos de dois meninos quebrarem os ovos. $\mathrm{Na}$ interpretação em (24b), o distribuidor é novamente ocasiões e o distribuído é novamente eventos de meninos quebrarem ovos, só que nesse caso, o que é determinado é o número de ovos e não o de meninos. Baseados apenas nessas duas sentenças, poderíamos observar que o operador 'de x em x' tem sempre como distribuidor 'ocasiões', e como distribuído o tipo de evento denotado pela sentença. ${ }^{12} \mathrm{O}$ que parece diferenciar uma e outra de suas leituras é se o que é determinado é o número - a cardinalidade - do sujeito (24a) ou a cardinalidade do objeto $(24 \mathrm{~b}) .{ }^{13}$

Se compararmos a sentença (24) do português - Meninos quebraram ovos de dois em dois - a sua semelhante em karitiana (23) - Õwã nakakot sypomp sypomp opokakosypi - vemos que elas não possuem exatamente as mesmas interpretações. A sentença do português não possui a interpretação na qual - necessariamente cada menino quebrou dois ovos, ou seja, na qual o distribuidor é o sujeito e é o

${ }^{12} \mathrm{O}$ que conta como uma ocasião é determinado pelo contexto e pode, às vezes, estar linguisticamente expresso, como em "Meninos quebraram ovos de dois em dois uma vez por dia" ou "Cada vez que João apitou, os meninos quebraram dois ovos".

${ }^{13}$ A semântica de expressões adverbiais com reduplicação de numerais no português não será discutida neste trabalho. Trata-se de um estudo ainda a ser feito para o português brasileiro. 
MÜLLER - Distributividade: o caso dos numerais reduplicados em Karitiana

objeto direto que tem sua cardinalidade determinada. Por outro lado, a sentença do karitiana não possui a interpretação na qual o distribuidor são ocasiões e o distribuído são meninos (dois meninos distribuídos por cada vez - a interpretação (24a)).

Vamos agora examinar com mais detalhe os numerais distributivos do karitiana. Primeiramente, é importante notar que os numerais distributivos geram apenas leituras distributivas, ao contrário das sentenças despidas de operadores discutidas na seção 4. Para que isso fique claro, vamos comparar a sentença (5) Õmbaky naka'yt pikom - discutida na seção 4 com a sua correspondente com um numeral distributivo, a sentença (6) - Myhint myhint õmbaky naka'yt pikom.

Como já dissemos, a sentença (6), com o numeral distributivo myhint myhint ('um um'), é verdadeira apenas em contextos distributivos: um contexto no qual cada onça come um macaco; ou um contexto em que, onças coletivamente comem um macaco de cada vez. As interpretações cumulativa e coletiva, como aquelas possíveis para a sentença (5), em que, por exemplo, duas onças comem um macaco juntas e uma outra come um macaco sozinha ou uma situação na qual todas as onças comem um único macaco juntas, não são possíveis para a sentença (6). $\mathrm{O}$ crucial aqui é lembrar que para a sentença com o numeral distributivo, sempre temos um macaco por onça ou um macaco por ocasião, ou seja, sempre temos mais de um macaco.

O contraste entre os significados das sentenças (5) e (6) é similar ao argumento de Kratzer (2003) a favor da existência tanto de plural (cumulatividade) lexical quanto de plural (distribuição) do VP. O argumento da autora foi apresentado na seção 3. Aqui, vamos mostrar que um fato paralelo ocorre no karitiana. Em karitiana, a sentença (25) abaixo, que é a versão com apenas um numeral de (5) e de (6), possui somente a interpretação na qual apenas um macaco é comido, independentemente do número de onças envolvidas na ação. Em outras palavras, essa sentença não é verdadeira em qualquer situação, distributiva ou não, que envolva mais de um macaco. É importante notar que o que está acontecendo é que o numeral fixa o número de macacos passíveis de serem denotados pelo objeto direto e, como não é possível comer um mesmo macaco mais de uma vez, fixa também o número de eventos denotados pelo predicado, impossibilitando que o predicado tenha outras interpretações de número permitidas pelo significado lexical de seu verbo e de seu objeto.

$\begin{array}{clll}\text { (25) Õmbaky } & \text { naka'yt } & \text { myhint } & \text { pikom. } \\ \text { õmbaky } & \text { Ø-naka--'y-t } & \text { myhin-t } & \text { pikom } \\ \text { onça } & \text { 3-DECL-CAUS-comer-NFT } & \text { um-oBL } & \text { macaco }\end{array}$

'Onças comeram um macaco'

Note-se que a diferença entre as sentenças (6) e (25) está no numeral distributivo. Deduzimos então que é esse numeral distributivo que gera a leitura distributiva e que é ele, portanto, que pluraliza o predicado verbal. Pluralizar o predicado em (25) significa gerar mais de um evento de 'comer um macaco'. 
Nesta seção, vimos que os numerais distributivos efetuam sempre uma operação de distribuição. Vimos também que essa operação realiza necessariamente uma pluralização do predicado verbal. Assim, concluímos que a interpretação distributiva gerada pela cumulatividade lexical se distingue da interpretação distributiva gerada pelos numerais distributivos. Na próxima seção, apresentaremos nossa análise para sentenças com numerais distributivos no karitiana.

\section{ANÁLISE DOS NUMERAIS DISTRIBUTIVOS}

Nesta seção, investigaremos os mecanismos da operação semântica realizada pelos numerais reduplicados do karitiana. Vamos defender a hipótese de que esses operadores, apesar de tomarem como seu distribuidor tanto o sujeito da sentença como 'ocasiões' (ou 'vezes'), não são operadores ambíguos. Nossa tese é a de que essas duas opções são resultado da possibilidade de uso de diferentes modos de individuação dos subeventos na denotação do predicado verbal (da pluralização, portanto). No caso em discussão, os subeventos são individualizados ou a partir dos participantes do evento (o sujeito) ou a partir de 'ocasiões' ou 'vezes' dadas pelo contexto. Podemos simbolizar inicialmente essa operação como em (26). Sua particularização para a sentença (6) seria (27).

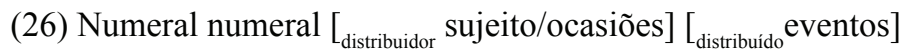
(27) Myhint myhint [onças/ocasiões] [subeventos de comer macaco]

O fato de termos um único quantificador sobre subeventos e não uma ambigüidade entre um quantificador nominal e um quantificador adverbial implica que esse operador deve ser analisado como um operador adverbial em todas as suas ocorrências. Como já dissemos, a individuação dos subeventos criados pela operação de pluralização será dada pelo distribuidor que pode ser tanto o sujeito - ombaky, em nosso exemplo - ou ocasiões ('vezes') dadas contextualmente. No caso do exemplo (44), as ocasiões poderiam ter sido dadas por eventos de onça aparecer perto da aldeia.

Além disso, como já pôde ser percebido a partir dos exemplos de sentenças com numerais distributivos, vimos que eles impõem uma restrição de cardinalidade a um dos argumentos nominais da sentença. Na seção anterior, discutimos a sentença (6), nas qual o argumento que tem sua cardinalidade determinada é sempre o objeto direto ou indireto, nunca o sujeito. Vamos agora examinar sentenças com apenas um argumento como (28).

Em sentenças com verbos intransitivos os numerais distributivos geram apenas a leitura em que o distribuidor são ocasiões e o distribuído são os eventos denotados pelo predicado. E, neste caso, é o sujeito que tem sua cardinalidade determinada. Essa sentença não têm uma leitura em que o distribuidor é o sujeito. Em (28), apresentamos uma sentença intransitiva com numeral distributivo e em (29) representamos a estrutura lógica dessa sentença. Uma leitura para essas 
MÜLLER - Distributividade: o caso dos numerais reduplicados em Karitiana

sentenças na qual o distribuidor fosse o sujeito (as paráfrases com o quantificador todos/as), talvez porque nesse caso não haveria argumento para o qual a cardinalidade pudesse ser determinada.

$\begin{array}{lll}\text { (28) Sypompt.sypomp } & \text { naotãm } & \text { taso } \\ \text { sypom-t.sypom-t } & \emptyset \text {-na-otãm- } \varnothing & \text { taso } \\ \text { dois-OBL.dois-oBL } & \text { DECL-ir-NFT } & \text { homem } \\ \text { *‘Todos os homens chegaram' } & \\ \text { 'Os homens chegaram de dois em dois' } \\ \text { ('Em cada ocasião, chegaram dois homens') }\end{array}$

(29) Sypomp.sypomp [ocasiões][subeventos de os homens chegarem].

Nossa proposta aqui é a de que o argumento que tem sua cardinalidade interna determinada pelo numeral distributivo é sempre um argumento interno do predicado verbal. Como estamos adotando o formalismo de Kratzer (2003, 2005), assumimos que o sujeito e o argumento 'ocasiões' são externos ao predicado verbal. No caso dos verbos intransitivos, vamos assumir, juntamente com Storto \& Rocha no prelo que esses verbos são todos inacusativos na língua karitiana. A evidência principal para esse tipo de análise vem do fato de que os verbos em karitiana concordam com seus objetos diretos em sentenças transitivas e com seus 'sujeitos' em sentenças intransitivas.

Em outras palavras, propomos as seguintes generalizações sobre os numerais distributivos em karitiana: (i) eles não pertencem ao sistema nominal, ou seja, não são quantificadores de determinante, mas sim quantificadores adverbiais; (ii) o distribuído são sempre eventos, pois é o predicado verbal que é pluralizado; (iii) o distribuidor é um argumento externo ao predicado, no caso, o sujeito ou ocasiões fornecidas pelo contexto ('vezes'); e (iv) a restrição sobre a cardinalidade se dá apenas sobre o argumento interno ao predicado verbal.

A argumentação a favor de que o numeral distributivo é um quantificador adverbial (i) será desenvolvida na próxima seção. Vejamos então como (ii)-(iv) descrevem o comportamento da sentença (6). Uma primeira aproximação do significado da sentença (6) é a paráfrase 'Existe um evento plural de comer macacos cujo agente são onças e, para cada sub-evento desse evento plural, há um macaco que é comido'. Essa paráfrase está representada na forma lógica em (30a).

(30a) (i) $\exists \mathrm{E} \exists \mathrm{X} \exists \mathrm{Y}[[$ agente $(\mathrm{X})(\mathrm{E})$ \& onça $(\mathrm{X})$ comer $(\mathrm{Y})(\mathrm{E})$ \& macaco $(\mathrm{Y})$ \& (ii) $\forall$ e $\exists y$ [e $\leq$ E \&átomo (e) \& E $\geq 2 \& Y \geq 2 \rightarrow \operatorname{comer}(y)$ (e) \& y $\leq \mathrm{Y} \&$ $|\mathrm{y}|=1]]^{14}$

Note-se que a primeira linha da fórmula acima (i) é exatamente a forma lógica de Ombaky naka'yt pikom, ou seja, é a forma lógica da mesma sentença

\footnotetext{
${ }^{14}$ Onde: X, Y são variáveis sobre entidades plurais; y é variável sobre entidades singulares; E é variável sobre eventos plurais; e é variável sobre eventos singulares.
} 
que Myhint myhint ombaky naka’yt pikom, exceto pela presença do numeral distributivo. Assim, o significado de uma sentença com numeral distributivo é composto a partir do significado da mesma sentença sem esse numeral. ${ }^{15} \mathrm{~A}$ segunda sentença da fórmula (ii) é a que expressa a pluralização dos eventos e a exigência de uma cardinalidade determinada para o objeto.

A forma lógica em (30a), entretanto, ainda é incompleta como representação do significado de (6). Nela, nada garante, na leitura em que o distribuidor é o sujeito, que o número das onças que comem um macaco é sempre um. Ela seria verdadeira, por exemplo, em uma situação em que duas onças comem junto um macaco e uma terceira onça come sozinha um outro macaco. ${ }^{16} \mathrm{~A}$ forma lógica em (30a) também não garante, na leitura iterativa, que os tempos (as ocasiões) em que ocorrem os eventos de comer um macaco sejam descontínuos.

Assim, seguindo a proposta de Lasersohn para os pluracionais, introduziremos uma nova sentença nessa fórmula e ela servirá para garantir que os agentes devem ser atômicos e que os tempos não devem ser contínuos. A nova forma lógica está expressa em (30b), na qual a sentença acrescentada (iii) afirma que todos os eventos atômicos pertencentes ao evento maior ou ocorrem em tempos distintos ou possuem agentes distintos e que esses agentes são atômicos (na leitura em que o sujeito é o distribuidor). Não podemos afirmar que os agentes são sempre atômicos porque na leitura em que o distribuidor são ocasiões, o agente pode ser plural.

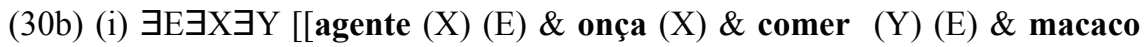
(Y)] \& (ii) $\forall$ e $\exists$ y $[\mathrm{e} \leq \mathrm{E} \&$ \&́tomo (e) \& $|E| \geq 2 \&|Y| \geq 2 \rightarrow \operatorname{comer}(\mathrm{y})$ (e) \& $y \leq Y \&|y|=1] \&$ (iii) $\forall \mathrm{e}^{\prime}, \mathrm{e}^{\prime \prime}\left[\mathrm{e}^{\prime}, \mathrm{e}^{\prime \prime}<E \&\right.$ átomo $\left(\mathrm{e}^{\prime \prime}\right) \rightarrow\left[\neg\left[\tau\left(\mathrm{e}^{\prime}\right){ }^{\circ} \tau\left(\mathrm{e}^{\prime \prime}\right)\right]\right.$ $\left.\left.\mathrm{V}\left[\neg\left[\theta \operatorname{Ag}\left(\mathrm{e}^{\prime \prime}\right)\right] \&\left[\left|\theta \operatorname{Ag}\left(\mathrm{e}^{\prime}\right)\right|=1 \&\left|\theta \operatorname{Ag}\left(\mathrm{e}^{\prime}\right)\right|=1\right]\right]\right]\right]$

onde: $\tau=$ intervalo de tempo; $\theta \mathrm{Ag}=$ papel temático do agente da sentença; as outras variáveis são como em (30a).

Nesta seção, defendemos que os numerais distributivos em Karitiana são operadores distributivos sobre eventos. Na próxima seção, vamos apresentar evidências que apoiam a análise de que os numerais distributivos são sempre quantificadores adverbiais e não operadores ambíguos entre quantificadores de determinante e quantificadores adverbiais.

\section{NUMERAIS DISTRIBUTIVOS SÃO SINTAGMAS ADVERBIAIS}

O objetivo desta seção é apresentar argumentos sintáticos e semânticos que sustentam a análise de que os numerais distributivos são sintagmas adverbiais

\footnotetext{
${ }^{15}$ Esse seria o ponto de partida para a descrição composicional do significado de sentenças com numerais distributivos. Um tratamento composicional completo fica para trabalhos futuros.

${ }^{16}$ Agradeço a um dos pareceristas anônimos por ter me apontado essa questão.
} 
MÜLLER - Distributividade: o caso dos numerais reduplicados em Karitiana

e não são ambíguos entre um quantificador de determinante e um quantificador adverbial. ${ }^{17}$

Primeiramente, as interpretações de sentenças com numerais distributivos independem da posição sintática desse operador. Não importa qual a posição em que esses operadores ocorram (respeitadas as posições gramaticais para sintagmas adverbiais), as possibilidades de interpretação são sempre as mesmas. Em segundo lugar, os numerais distributivos comportam-se exatamente da mesma maneira que outras expressões adverbiais em karitiana em relação às posições estruturais que podem ocupar. Assim como os outros advérbios da língua, os numerais distributivos em sentenças matrizes podem ocupar tanto a periferia esquerda como a direita e a posição entre o verbo e o objeto, sendo agramaticais na posição entre o sujeito e o verbo. ${ }^{18}$ As sentenças (31a-d) ilustram nossos dois argumentos.

\begin{tabular}{|c|c|c|c|}
\hline a. Myhint.myhint & nakam'at & gooj & õwã \\
\hline myhim-t.myhim-t & $\varnothing$-naka-m-’a-t & gooj & õwã \\
\hline um-OBL.um-OBL & 3-DECL-CAUS-construir-NFT & barco & criança \\
\hline
\end{tabular}
b. Õwã $\quad$ myhin-t.myhin-t gooj
criança 3-DECL-CAUS-construir-NFT um-OBL.um-OBL barco
'Cada criança construiu um barco'/
'Em cada ocasião, criança construiu um barco'
c. Õwã
Ø-nakam'at
gooj
myhin-t.myhin-t
criança
3-DECL-CAUS-construir-NFT barco
um-OBL.um-OBL
'Cada criança construiu um barco'/
'Em cada ocasião, criança construiu um barco'
d. *Õwã
myhin-t.myhin-t
Ø-nakam'at
gooj
criança
um-OBL.um-OBL
3-DECL-CAUS-construir-NFT
barco

Um terceiro argumento sintático que fundamenta o estatuto adverbial dos numerais distributivos é o fato de que outros quantificadores adverbiais que pluralizam eventos como kandat ('muitas vezes'), como ilustrado em (32), também segue esse mesmo padrão de distribuição sintática. ${ }^{19}$

\footnotetext{
${ }^{17}$ Müller \& Negrão no prelo argumentam extensivamente a favor da análise dos numerais distributivos do karitiana como sintagmas adverbiais. Esta seção apóia-se nessa argumentação.

${ }^{18}$ Para uma análise mais detalhada da distribuição e da estrutura das sentenças com sintagmas adverbiais em karitiana ver Müller \& Negrão no prelo e Storto 1999.

${ }^{19}$ Ver Sanchez-Mendes 2009 para uma análise detalhada de kandat como quantificador adverbial.
} 


$\begin{array}{llll}\text { (32) Kandat } & \text { jonso } & \text { nakaot } & \text { ese. } \\ \text { kandat } & \text { jonso } & \varnothing \text {-naka-ot- } \varnothing & \text { ese } \\ \text { kandat } & \text { mulher } & \text { 3-DECL-pegar-NFT } & \text { água } \\ \text { 'Mulher pegou água muitas vezes' } & \end{array}$

Nosso argumento final contra uma análise de numerais distributivos como quantificadores de determinante é baseado na estrutura dos NPs em Karitiana, que não possuem projeções funcionais manifestas. Como mencionado na seção 3, não há marcas morfossintáticas de número, classificadores ou (in)definitude no sistema nominal do Karitiana. ${ }^{20}$ Que apenas esses operadores formassem um constituinte com os SNs em karitiana iria de contra o padrão da língua.

Nesta seção, vimos que os numerais distributivos comportam-se tanto sintatica como semanticamente como sintagmas adverbiais. Consequentemente, temos aqui mais um argumento de que o numeral distributivo realiza sempre uma mesma operação e não gera sentenças estruturalmente ambíguas.

\section{CONCLUSÕES}

Neste artigo, argumentamos que existem (pelo menos) dois tipos de distributividade em Karitiana: distributividade gerada por cumulatividade lexical e distributividade gerada por numerais distributivos. Vimos que numerais distributivos são operadores distributivos que multiplicam os eventos na denotação do predicado verbal e impõem uma restrição sobre cardinalidade de seu argumento interno. Assim, as duas interpretações de uma sentença com numerais distributivos - ter o sujeito ou ocasiões como o distribuidor - têm sua origem nos diferentes critérios que podem ser usados para individualizar subeventos. Essa hipótese foi sustentada por evidências sintáticas e semânticas.

Em termos teóricos, concluímos que a semântica dos nomes e verbos em karitiana fornece evidências para a existência de (pelo menos) duas origens para pluralidade e distributividade: cumulatividade lexical e distribuição do VP, conforme proposto em Kratzer 2003, 2005.

\section{REFERÊNCIAS BIBLIOGRÁFICAS}

COUTINHO-SILVA, T. (2009). Aspectos dos sintagmas nominais em karitiana: a quantificação universal. Tese de mestrado, Universidade de São Paulo, 2009.

DAVIDSON, D. (1967). The Logical Form for Action Sentences. In: RESCHER, N. (ed.) The Logic of Decision and Action. Pittsburgh: University of Pittsburgh Press. p. 81-95.

GIL, D. (1982). Distributive Numerals. Ph. D. Dissertation, University of California, Los Angeles.

${ }^{20}$ Ver Müller, Storto \& Coutinho-Silva para uma descrição e análise dos sintagmas nominais em karitiana. 
MÜLLER - Distributividade: o caso dos numerais reduplicados em Karitiana

GIL, D. (2011). Distributive Numerals. In: DRYER, M. S. \& HALPELMATH, M. (eds.) The World Atlas of Language Structures Online. Munich: Max Planck Digital Library, 2011, chapter 54. Available online at http://wals.info/chapter/1. Accessed on 2011-09-03.

KRATZER, A. (2008). The Event Argument and the Semantics of Verbs. 2003. http://semanticsarchive. net. Accessed on 5/05/2008.

. (2005). A. On the Plurality of Verbs. In: DÖLLING, J. \& HEYDE-ZYBATOW, T. (eds.), Event Structures in Linguistic Form and Interpretation. Berlin: Mouton de Gruyter, Berlin.

KRIFKA, M. (1992). Thematic Relations as Links Between Nominal Reference and Temporal Constitution. In: SAG, I. \& SZABOLCSI, A. (eds.), Lexical Matter. Chicago: CSLI. p. 29-53.

LANDMAN, F. (1996). Plurality. In: LAPPIN, S. The Handbook of Contemporary Semantic Theory. Oxford: Blackwell. p. 425-457.

LASERSOHN, P. (1995). Plurality, Conjunction, and Events. Dordrecht, Boston: Kluwer Academic Publishers.

. (1998). Generalized Distributivity Operators. Linguistics and Philosophy 21 (1). p.83-93.

LINK, G. (1983). The Logical Analysis of Plurals and Mass Terms: a Lattice-Theoretical Approach. In: BAUERLE, R.; SCHWARZE, C. \& von STECHOW, A. (eds.). In: Meaning, Use and Interpretation of Language. Berlin, New York: de Gruyter. p. 302-323.

. (1987). Generalized Quantifiers and Plurals. In: Peter Gärdenfors (ed.). Generalized Quantifiers: Linguistic and Logical Approaches. Dordrecht: D. Reidel. p. 151-180.

MATTHEWSON, L. On Distributivity and Pluractionality. In: JACKON, B. \& MATTHEWS, T. (eds.) Proceedings of SALT X. Ithaca, NY: CLC Publications. 17 pages.

. (2004). On the Methodology of Semantic Fieldwork. International Journal of American Linguistics 70, 2000. p. 369-415.

MÜLLER, A.; SANCHEZ-MENDES, L. (2008). Pluractionality in Karitiana. Proceedings of Sinn \& Bedeutung 12, Oslo: Department of Literature, Area Studies and European Languages, University of Oslo, 2008. 442-454.

. (2010). O Significado da Pluracionalidade em Karitiana. Cadernos de Estudos Lingüísticos (UNICAMP), v. 52, p. 215-231.

MÜLLER, A.; STORTO, L.; COUTINHO-SILVA, T. (2006). Number and the count-mass distinction in Karitiana. University of British Columbia Papers in Linguistics - UBCWPL 19: Proceedings of the Eleventh Workshop on Structure and Constituency in Languages of the Americas, 2006. p. 122-135.

PARSONS, T. (1990). Events in the Semantics of English: A Study in Subatomic Semantics. Cambridge: MIT Press.

SANCHEZ-MENDES, L. (2009). A quantificação adverbial em Karitiana. Dissertação de mestrado, USP.

SCHEIN, B. (1993). Plural and Events. Cambridge: MIT Press.

STORTO, L. (1999). Aspects of Karitiana Grammar. MIT Ph.D. dissertation. (2010). Copular Constructions in Karitiana: A Case Against Case Movement. In: University of Massachusetts Occasional Papers 41. Proceedings of Semantics of Under-represented Languages in the Americas 5. Amherst: GLSA, 2010. p. 205-226. 
Cadernos de ESTUDOS LINGǘlSTICOS (54.2) - Ju1./Dez. 2012

STORTO, L.; ROCHA, I. Strategies of Valence Change in Karitiana. In: TELLES, S.; BRUNO, A. C.; QUEIXALOS, F. (eds.). Valence Increasing Processes in Amazonia. Bogota: Universidad Nacional de Colombia.

STORTO, L.; van der VELDEN, F.F. (2005). Karitiana. In: Povos Indígenas do Brasil. In: http: //pib. socioambiental.org/pt/povo/karitiana. Accessed on 5/05/2008. 
